() (1) https://creativecommons.org/licenses/by/4.0/

Privatização da e na educação infantil

\title{
AS INSTITUIÇÕES SEM FINS LUCRATIVOS NA PRIVATIZAÇÃO DA EDUCAÇÃO INFANTIL
}

\author{
MARIA LUCIA LEMOS CECCON ${ }^{1}$ \\ ORCID: http://orcid.org/0000-0002-2334-7352 \\ NADIA PEDROTTI DRABACH ${ }^{2}$ \\ ORCID: http://orcid.org/0000-0002-0076-6183
}

\begin{abstract}
RESUMO: Este artigo resultou de pesquisa concluída sobre a participação das instituições sem fins lucrativos na oferta de vagas na Educação Infantil (EI) sob responsabilidade da Prefeitura Municipal de Campinas (PMC), no período de 2007 a 2018. Objetivou compreender a natureza e a atuação dessas instituições no atendimento da EI à luz dos processos de privatização da Educação Básica. A pesquisa utilizou-se de fontes primárias consultadas nos sites da PMC, no Portal de Estatísticas do Estado de São Paulo (Seade), no Fundo Nacional de Desenvolvimento da Educação (FNDE) e nos microdados do Censo Escolar. Os resultados do estudo apontaram transformações e (in)adequações político-normativas na (re)constituição das instituições sem fins lucrativos, com vistas a ampliar o atendimento às demandas de EI do município. Além disso, evidenciou-se a opção da PMC pela expansão da oferta privada da EI por meio das instituições sem fins lucrativos em detrimento da oferta pública direta.
\end{abstract}

Palavras-chave: Instituições Sem Fins Lucrativos, Educação Infantil, Privatização da Educação, Convênio.

\section{NON-PROFIT INSTITUTIONS IN THE PRIVATIZATION OF EARLY CHILDHOOD EDUCATION}

\begin{abstract}
This article results of a concluded research on the participation of non-profit institutions in the offer of Early Childhood Education (EI) under the responsibility of the Municipality of Campinas (PMC), from 2007 to 2018. It aimed to understand the nature and performance of these institutions in the attendance of EI in relation to the processes of privatization of Basic Education. The research was based on primary sources consulted on the PMC sites, the Statistics Portal of the State of São Paulo (Seade), the National Fund for the Development of Education (FNDE) and the microdata of the School Census. The results of the study pointed to transformations and political-normative (in)adequacy in the (re)constitution of non-profit institutions, aiming to better meet the demands of EI of the municipality. In addition, it showed the option of PMC for expanding the offer of private EI through non-profit institutions to the detriment of the direct public offering was evidenced.
\end{abstract}

Keywords: Non-Profit Institutions, Child education, Privatization of Education, Public Agreement.

\footnotetext{
${ }^{1}$ Universidade Estadual de Campinas - Unicamp. Campinas, SP, Brasil. <maluciaceccon@hotmail.com>

2 Professora do Instituto Federal de Educação, Ciência e Tecnologia de São Paulo - IFSP. Hortolândia, SP, Brasil.

$<$ nadiapdrabach@gmail.com>
} 


\section{INSTITUCIONES SIN FINES DE LUCRO EN LA PRIVATIZACIÓN DE LA EDUCACIÓN DE LA PRIMERA INFANCIA}

RESÚMEN: Este artículo presenta los resultados de una investigación terminada sobre la participación de instituciones sin fines de lucro en la oferta de plazas para la educación infantil (EI) bajo la responsabilidad del Ayuntamiento de Campinas (PMC), de 2007 a 2018. Su objetivo era comprender la naturaleza y la actuación de estas instituciones en el atendimiento de la Educación Infantil a la luz de los procesos de privatización de la Educación Básica. La investigación utilizó fuentes primarias consultadas en los sitios web del Ayuntamiento, el Portal de Estadísticas del Estado de São Paulo (Seade), el Fondo Nacional de Desarrollo de la Educación (FNDE) y los microdatos del Censo Escolar. Los resultados del estudio apuntaron transformaciones e (in)adecuaciones político normativas en la (re)constitución de las instituciones sin fines de lucro, con intenciones de ampliar la asistencia a las demandas de EI del municipio. Además, se evidenció la opción de la administración municipal de expandir la oferta privada de EI a través de instituciones sin fines de lucro en detrimento de la oferta pública directa.

Palabras clave: Instituciones sin fines de lucro, Educación Infantil, Privatización de la educación, Pacto.

\section{INTRODUÇÃO}

Este estudo analisa a presença e a atuação das instituições sem fins lucrativos classificadas como associações ou fundações de natureza privada sem fins lucrativos, que atuam com o governo do município de Campinas, São Paulo, na execução de atividades de Educação Infantil (EI). Incluiram-se ainda na análise alguns elementos referentes às Organizações Sociais (OSs), uma vez que essas instituições também participam como uma das modalidades de oferta da EI no município de Campinas, no período compreendido pela série histórica.

Segundo o Código Civil Brasileiro, lei n. ${ }^{\circ}$ 10.406/2002, associação e fundação são os dois modelos possíveis de constituição de pessoas jurídicas, conhecidas como integrantes do chamado terceiro setor e/ou Organizações da Sociedade Civil (OSCs). A associação privada é formada pela união de pessoas que se organizam para fins não econômicos, ao passo que a fundação, também pessoa jurídica sem fins lucrativos, se forma a partir da existência de um patrimônio, por meio de escritura pública em testamento, para servir a um objetivo específico estatutário, voltado às causas de interesse público (BRASIL, 2002). No caso do município de Campinas, a associação privada é a modalidade jurídica predominantemente adotada, normalizada por meio do termo de colaboração, a partir de 2017 , em decorrência da exigência da lei n. ${ }^{\circ}$ 13.019/2014.

As OSs, também consideradas entidades sem fins lucrativos de direito privado, diferem das demais por se constituírem via fomento do poder público para sua criação e fornecimento de qualificação (DI PIETRO, 2015). São regidas pelo contrato de gestão, conforme lei n. ${ }^{\circ} 9.637 / 1998$, e por lei complementar estadual e municipal. Segundo Di Pietro (2015, p. 263), “[...] elas, como regra geral, prestam serviço público por delegação do poder público, [...] utilizando-se de patrimônio público, muitas vezes contando com servidores públicos em seu quadro de pessoal".

A formalização das instituições sem fins lucrativos possibilita que as entidades e seus doadores tenham acesso aos benefícios fiscais e às verbas públicas, além de lhes fornecer habilitação para a celebração de contratos com os órgãos da administração pública. Como exigência para celebração de contratos, as instituições privadas necessitam solicitar junto aos órgãos competentes os títulos de qualificação como Organizações da Sociedade Civil de Interesse Público (OSCIPs), Utilidade Pública Estadual (UPE) e Municipal (UPM) e/ou mais recentemente o CEBAS/Educação ${ }^{3}$, conforme lei n. ${ }^{\circ}$

\footnotetext{
3 A Certificação de Entidades Beneficentes de Assistência Social na Área da Educação (CEBAS/Educação), regulamentada pela Lei n. ${ }^{\circ}$ 12.101/2009 e alterações posteriores, constitui um marco regulatório na normatização para as políticas de transferências da oferta da educação pública ao setor privado sem fins lucrativos. Essa certificação passa a ser fornecida pelo Educação em Revista|Belo Horizonte |v.36|e231107|2020
} 
12.101/2009 e alterações posteriores, considerado como um marco regulatório na normatização para as políticas de transferências da oferta da educação pública ao setor privado denominado "sem fins lucrativos".

A pesquisa considerou os anos de 2007 a 2018, por ser o período de criação do Fundo de Manutenção e Desenvolvimento da Educação Básica e de Valorização dos Profissionais da Educação (FUNDEB), instituído e regulamentado pela lei n. ${ }^{\circ} 11.494 / 2007$. De acordo com a referida lei, segundo o artigo $8^{\circ}, \int 3^{\circ}$, a distribuição dos recursos do fundo passou a considerar também o cômputo das matrículas ofertadas pelas instituições privadas sem fins lucrativos, desde que conveniadas com o poder público. Com isso, foi possível pensar que, além dos incentivos fiscais disponibilizados às instituições privadas, as condições favoráveis de acesso às verbas públicas do Fundeb podem ser consideradas elemento indutor na manutenção e/ou ampliação das instituições sem fins lucrativos no atendimento da EI de Campinas. Além disso, em 2007 inaugurou-se uma nova modalidade de oferta representada pelas unidades públicas com gestão privada, inicialmente denominadas Naves-mãe, estudada por DomicianoPellisson (2016) e mais tarde também chamada de Bem Querer, o que corroborou para o aumento da oferta de vagas privatizadas da EI em Campinas.

O presente trabalho entende como vaga privatizada aquela demandada ao serviço público, porém ofertada por uma das duas modalidades vinculadas: rede conveniada e unidades públicas com gestão privada (Nave-mãe/Bem querer), as quais recebem valores per capita do poder público municipal para prover o atendimento da EI no município. As modalidades serão melhor caracterizadas na segunda e terceira parte desse trabalho.

A pesquisa valeu-se do uso de fontes primárias para a obtenção de dados, tais como documentos legais e normativas, encontrados nos sites governamentais. Utilizou-se também de páginas oficiais e não oficiais das instituições sem fins lucrativos para caracterizá-las quanto à natureza e ao perfil social. E, para a obtenção das taxas de matrículas na Educação Infantil, fez-se uso das informações publicadas pelo Portal de Estatísticas do Estado de São Paulo (SEADE) e dos microdados do censo escolar publicados pelo Instituto Nacional de Estudos e Pesquisas Educacionais Anísio Teixeira (INEP), cuja leitura foi realizada por meio do software de análises estatísticas nas ciências sociais (SPSS). O trabalho buscou analisar a evolução das matrículas de EI no município de Campinas, por dependência administrada, com o foco nas três modalidades assim distribuídas: oferta pública direta, oferta conveniada e unidades públicas com gestão privada, influenciada pela política de fundos que possibilitou também contabilizar as matrículas conveniadas.

Além da introdução que constitui a primeira parte, este texto apresenta ainda mais três tópicos. No primeiro deles, constrói-se uma breve digressão histórica destacando as origens e a natureza das Instituições sem fins lucrativos, apontando para a sua expansão no atendimento da Educação Infantil em Campinas ao longo do século XX e início do século XXI e para o tipo de relação estabelecida com a SME para a oferta de EI. No segundo tópico, analisam-se as normativas que regulamentam a prestação de Serviços de Educação Infantil pelas entidades no município de Campinas, especialmente os acordos estabelecidos entre o governo municipal e as instituições sem fins lucrativos normalizadas pelo Termo de Convênio, Termo de Colaboração ou Contrato de Gestão, a depender da natureza dessas instituições. O terceiro tópico apresenta as vias pelas quais ocorreu a oferta de vagas de Educação Infantil no município de Campinas no período de 2007 a 2018, a saber: pública direta, rede conveniada e Centros de Educação Infantil públicos com gestão privada. Analisa-se o movimento de expansão do setor privado, principalmente por meio das instituições sem fins lucrativos; e, para finalizar a pesquisa, apontase para a evidência que mostra a opção do governo municipal pela expansão da oferta de vagas privatizadas, cujo movimento alterou o perfil da oferta de EI no município de Campinas.

governo federal, Ministério da Educação (MEC), e possibilita às entidades detentoras do CEBAS poderem “usufruir de isenção do pagamento das contribuições sociais, incidentes sobre a remuneração paga ou creditada aos seus empregados. Também podem receber transferências de recursos governamentais a título de subvenções sociais, nos termos da Lei de Diretrizes Orçamentárias (LDO) vigente. O certificado CEBAS é um dos documentos exigidos pela Receita Federal do Brasil (RFB) para que as entidades privadas, sem fins lucrativos, gozem da isenção da cota patronal das contribuições sociais." (BRASIL, 2015, p. 5) 

para designar

O termo privatização utilizado neste trabalho associa-se ao termo referido por Adrião (2015)

o movimento que tem direcionado a educação básica pública brasileira para o campo e sob o interesse do setor privado corporativo, lucrativo ou não, ou a este associado [...]. Trata-se de processos pelos quais a educação pública brasileira se subordina ao setor privado (ADRIÃO, 2015, p. 7-8).

Ademais, a pesquisa indica que o fortalecimento desta modalidade de atendimento retomou as características assistenciais alternativas, provisórias e precárias às crianças pequenas, dificultando avanços na construção de um atendimento referenciado, qualificado e que, de fato, assegure os direitos ao ensino laico, público e de qualidade, proclamados na constituição cidadã. Apesar de a CF/1988 declarar em seu artigo 213 , parágrafo $1^{\circ}$, que os recursos públicos devam ser aplicados prioritariamente na rede pública direta, observaram-se, nessa última década, manobras dos gestores públicos no sentido de desconsiderar o princípio fundamental da Carta, ampliando exclusivamente o atendimento por meio do setor privado denominado "sem finalidade lucrativa".

\section{AS INSTITUIÇÕES SEM FINS LUCRATIVOS DO MUNICÍPIO DE CAMPINAS EM ATUAÇÃO NA EI, VINCULADAS À SME NO PERÍODO 2007 A 2018: BREVE HISTÓRICO}

O presente estudo evidenciou a participação histórica das entidades sem fins lucrativos no atendimento à criança pequena no município de Campinas. A partir de tal estudo, pode-se afirmar que a Educação Infantil no município "nasceu nos braços" das instituições privadas sem fins lucrativos.

Os primeiros registros de instituições que atendiam crianças pequenas em Campinas remontam ao início do século XX. A primeira unidade a ser nomeada como creche no município foi a creche Bento Quirino, construída em 1914 com donativos do Major Bento Quirino, em terreno doado pela Câmara Municipal. Em 1916, com um grupo de senhoras católicas, o Bispo Dom Nery fundou a Sociedade Feminina de Assistência à Infância, com a finalidade de gerir a creche (IBGE, 1952). Com mais de 100 anos de existência, a entidade ainda hoje atua no atendimento de crianças da EI, subsidiada pela PMC (CECCON, 2018).

A partir de meados do século passado, o atendimento da criança pequena em Campinas coexistiu com diferentes modelos de atendimento: a rede privada stricto sensu, as instituições conveniadas e a rede pública direta. Inicialmente, os atendimentos na EI, durante a primeira metade do século passado, eram majoritariamente feitos pelas instituições assistenciais. Mesmo com o início do aparelhamento público para oferta da EI a partir de 1940, com os primeiros parques infantis, e em 1968 com a primeira creche pública da cidade, as instituições privadas sem fins lucrativos permaneceram com os atendimentos em grande parte subsidiados pelo poder público. Isso foi constatado no cadastramento municipal da PMC de 1944 a 1964, em atendimento ao decreto-lei n. ${ }^{\circ}$ 239/1944, cujo registro apontou pelo menos 24 instituições que ofertavam atendimento às crianças, subsidiadas pelo poder público (CECCON, 2018).

Nas décadas de 1970 e 1980, com o movimento de ampliação das salas de pré-escolas comunitárias, novamente as instituições sem fins lucrativos se fortaleceram e assumiram papel relevante no atendimento da criança pequena, subsidiadas por meio de programas do Governo Federal/MEC. Conforme o Quadro 1, 14 entidades (ou seja, 31\%) em atuação no período de 2007 a 2018 foram criadas nesse período.

$\mathrm{Na}$ década de 1990, as entidades ganharam novo impulso com o Plano Diretor da Reforma do Aparelho do Estado - PDRAE (1995) -, elaborado durante o governo FHC, que viu no "Terceiro Setor" a possibilidade de transferência da oferta dos serviços sociais. A partir da EC 19/98, foram introduzidas no ordenamento jurídico brasileiro as agências executivas (lei n. ${ }^{\circ}$ 9.649/98) e as organizações sociais (lei n. ${ }^{\circ}$ 9637/98), provocando mudança significativa na estrutura da administração pública no Brasil (SILVA, 1999). A EC 19 estabeleceu o contrato de gestão como instrumento de formalização das relações entre as agências executivas e as organizações sociais e o Estado.

A partir dessas alterações na legislação federal, as demais esferas da Administração Pública (estados e municípios), que já mantinham vínculos com as instituições sem fins lucrativos, parecem ter visto na nova lei uma oportunidade para ampliar o atendimento dos serviços sociais, dentre eles os 
relacionados à EI. Essas normativas podem ter induzido o aumento da criação de entidades sem fins lucrativos em Campinas, como demonstra o Quadro 1. De 1990 até 2007, 15 novas entidades foram criadas no município, o que representou $33 \%$ do total.

As instituições privadas estão classificadas na Lei de Diretrizes e Bases da Educação Nacional (LDB), lei n. ${ }^{\circ}$ 9394/96, em seu art. 20, como particulares, filantrópicas, comunitárias e confessionais. Entretanto, apenas essa classificação não foi suficiente para compreender a complexidade das instituições sem fins lucrativos em atuação na EI, vinculadas ou conveniadas à SME de Campinas. Observou-se que elas apresentavam ainda perfis e características diferentes entre si, a depender do contexto histórico e político em que surgiram, bem como das práticas que assumiram e que assumem na atualidade.

Para melhor compreensão da natureza destas instituições vinculadas à SME no período de 2007 a 2018, no atendimento da Educação Infantil em Campinas, elas foram classificadas e agrupadas por Ceccon (2018), de acordo com suas características, em históricas, tradicionais e contemporâneas:

As Históricas são definidas como entidades filantrópicas caritativas, fundadas basicamente por instituições religiosas como forma de combater a miséria social. Surgiram numa concepção assistencial como responsáveis pela questão social emergida da relação capitalista dos "sem direitos"; possuem dependência própria e geralmente são administradas por membros religiosos; e contam com o apoio do Estado, mas também possuem meios de se auto financiarem. As tradicionais, embora possuam dependências físicas próprias como as históricas, normalmente estão localizadas nas regiões mais distantes do centro, e têm como característica básica a participação da comunidade local e o desejo de "construir" uma sociedade melhor. Embora reconheçam a necessidade de "ter direito a ter direitos", mantêm a prática assistencial das históricas e possuem características bastantes semelhantes às "comunitárias", que emergiram nas décadas de 1970 e 1980. Necessitam fundamentalmente de recursos do Estado para seu funcionamento. As contemporâneas têm sua origem no início desse século, na emergência das alterações normativas, resultado das políticas de transferência das atividades sociais do Estado para o chamado "terceiro setor". São destituídas de dependência física para sua atuação, pois atuam em dependências públicas, necessitando apenas de um endereço para a sua formalização. Essas instituições podem surgir a partir das conveniadas históricas ou tradicionais, normalmente como filiais, ou mesmo criadas exclusivamente para gerir unidades públicas, como as OS, com grande capacidade de ampliação. Geralmente, possuem um escritório para gerir os negócios, em uma clara relação mercantil, e tem o Estado como seu financiador (CECCON, 2018, p. 77).

A partir dessa classificação, identificou-se que, embora as entidades históricas e tradicionais pareçam pertencer ao passado, isso não se confirma. Elas foram encontradas em diferentes períodos históricos, e algumas recentemente criadas apresentam características semelhantes às que surgiram no início do século passado. As entidades privadas de perfil contemporâneo nascem a partir do estímulo das novas legislações para a transferência e/ou obtenção dos recursos públicos.

As instituições sem fins lucrativos vinculadas à SME de Campinas no período de 2007 a 2018 tiveram suas origens em diferentes períodos históricos, com características próprias do seu momento de criação. O Quadro 1 apresenta o número de instituições sem fins lucrativos, por período de criação e tipo de vínculo contratual estabelecido com SME.

Quadro 1 - Caracterização das instituições sem fins lucrativos de Campinas, vinculadas à SME no período de 2007 a 2018, para oferta de Educação Infantil, por ano de fundação e quanto ao instrumento de ajuste utilizado na relação contratual.

\begin{tabular}{|c|c|c|c|c|c|c|}
\hline \multirow{2}{*}{$\begin{array}{l}\text { Faixas de } \\
\text { ano de } \\
\text { fundação }\end{array}$} & \multicolumn{3}{|c|}{$\begin{array}{l}\text { ASSOCIAÇÕES PRIVADAS (por } \\
\text { período de criação) }\end{array}$} & \multicolumn{3}{|c|}{ Termo de ajuste } \\
\hline & $\begin{array}{l}\text { Total de } \\
\text { instituições }\end{array}$ & Percentual & $\begin{array}{l}\text { Total de } \\
\text { instituições } \\
\text { filiais }\end{array}$ & $\begin{array}{l}\text { Termo de } \\
\text { convênio/ } \\
\text { colaboração }\end{array}$ & $\begin{array}{l}\text { Contrato de } \\
\text { gestão }\end{array}$ & $\begin{array}{c}* \text { Modalidades } \\
\text { Termo de convênio } \\
\text { e Contrato de gestão }\end{array}$ \\
\hline
\end{tabular}




\begin{tabular}{|c|c|c|c|c|c|c|}
\hline 1914-1939 & 6 & $13 \%$ & 1 & 5 & & 1 \\
\hline 1940-1969 & 8 & $16 \%$ & 2 & 7 & 1 & - \\
\hline 1970-1989 & 14 & $31 \%$ & - & 12 & 1 & 1 \\
\hline 1990-2006 & 15 & $33 \%$ & 3 & 13 & 1 & 1 \\
\hline 2007-2018 & 3 & $7 \%$ & - & 1 & 2 & - \\
\hline Total 2018 & 46 & $100 \%$ & 6 & 38 & 5 & 3 \\
\hline
\end{tabular}

Fonte: atualizada a partir de Ceccon (2018).

*Os dados referem-se às unidades criadas ou que possuem filiais em atuação apenas como associação privada.

Conforme o quadro acima, existem 46 instituições sem fins lucrativos vinculadas à SME em atuação no atendimento da EI no município de Campinas, e, dentre elas, 6 são filiais, com novos registros jurídicos no Cadastro Nacional de Pessoa Jurídica (CNPJ). Oito entidades foram criadas entre os anos de 1940 e 1969, sendo que sete delas possuem características das conveniadas históricas e tradicionais, ligadas à SME pelo termo de convênio, e uma filial com característica das contemporâneas, normalizada por meio do contrato de gestão.

De 1970 a 1989, das 14 instituições criadas no período, 12 vinculam-se à SME por meio de termo de convênio; apenas uma por contrato de gestão e mais uma que atende a duas modalidades, termo de convênio e contrato de gestão. O período 1990 e 2006, conforme já destacado, foi o período no qual mais se criaram instituições sem fins lucrativos: 15 no total e mais 3 filiais. Destas, 13 são regidas pelo termo de convênio, uma delas por contrato de gestão e outra por termo de convênio e contrato de gestão.

De 2007 a 2018, foram criadas apenas quatro entidades, com o menor índice dos períodos, correspondente a 7\%. Com o perfil das entidades conveniadas tradicionais foi fundada apenas uma entidade com instalações próprias para atendimento da EI. As demais, de perfil contemporâneo, embora sejam classificadas como associação privada, não contam com instalações próprias para atendimento, e suas sedes estão situadas em salas comerciais ou residenciais. O vínculo com a SME foi formalizado por meio de contrato de gestão, o que, do ponto de vista jurídico, não seria indicado, uma vez que "a previsão da obtenção de recursos orçamentários e bens públicos, pelas organizações sociais, com dispensa de licitação conforme o definido no artigo 12 da lei n ${ }^{\circ} 9.637 / 98$, se constituiria em violação ao princípio da isonomia, sendo, portanto, inconstitucional” (ADRIÃO E BEZERRA, 2013, p. 260).

Com base no Quadro 1, observa-se que o termo de convênio foi o instrumento por excelência adotado para formalizar o vínculo entre a PMC e as instituições privadas conveniadas históricas e tradicionais para oferta da EI em Campinas até 2016, substituído pelo Termo de Colaboração a partir de 2017, em decorrência da lei no 13.019/2014.

Quanto ao perfil social e à orientação religiosa presente na maioria das instituições sem fins lucrativos, estas podem ser classificadas conforme a Tabela 1.

Tabela 1 - Associações privadas e OSs vinculadas à Secretaria Municipal de Educação de Campinas, por período de fundação, classificação social e orientação religiosa (2007-2018).

\begin{tabular}{|c|c|c|c|c|c|c|c|}
\hline $\begin{array}{c}\text { Associações Privadas e } \\
\text { Organização Social }\end{array}$ & $\begin{array}{l}\text { período de } \\
\text { fundação }\end{array}$ & $\begin{array}{r}1890- \\
1939\end{array}$ & $\begin{array}{r}1940- \\
1969\end{array}$ & $\begin{array}{r}1970 \\
1989\end{array}$ & $\begin{array}{r}1990- \\
2006\end{array}$ & $\begin{array}{r}2007- \\
2018\end{array}$ & Total \\
\hline & $\begin{array}{l}\text { Número de } \\
\text { Instituições }\end{array}$ & 6 & 8 & 14 & 15 & 3 & 46 \\
\hline \multirow[t]{3}{*}{ Classificação Social } & Comunitária & - & - & - & 7 & - & 7 \\
\hline & Confessional & - & - & - & - & - & - \\
\hline & Filantrópica & 6 & 8 & 14 & 7 & - & 35 \\
\hline
\end{tabular}

Educação em Revista|Belo Horizonte|v.36|e231107|2020 


\begin{tabular}{|c|c|c|c|c|c|c|c|}
\hline & Não identificado & - & - & - & 1 & 3 & 4 \\
\hline \multirow[t]{4}{*}{ Orientação Religiosa } & Católica & 5 & 3 & 8 & 2 & - & 18 \\
\hline & Evangélica & - & - & 2 & 3 & - & 5 \\
\hline & Espírita & 1 & 1 & 4 & 1 & - & 7 \\
\hline & Não identificada & - & 4 & - & 9 & 3 & 16 \\
\hline
\end{tabular}

Fonte: Ceccon (2018). Elaboração da autora com base em FNDE $^{4}$ e sites das instituições conveniadas. Os dados têm como referência o mês de maio.

Observa-se a prevalência das entidades filantrópicas em praticamente todos os períodos, exceto de 2007 a 2018. Uma das hipóteses para essa opção pode estar relacionada à busca de certificados assegurados às associações assistenciais, como o da filantropia. O certificado de filantropia possibilitaria às associações de assistência social o recebimento de recursos públicos e garantia da isenção de contribuições previdenciárias patronais, além de outros benefícios fiscais que fazem diferença significativa para o caixa dessas entidades. Entretanto, a partir de 2009, com a Lei do CEBAS/ Educação, anteriormente citada, essa exigência deixa de ser necessária para acessar tais benefícios.

As instituições comunitárias surgiram na década de 1990, pós-Constituição Federal $\mathrm{CF} / 1988$. Com base na definição do termo "comunitária", uma das características da instituição com esse perfil é a inclusão de representantes da comunidade como membros da entidade. Compreendendo 1990 como o período pós-abertura democrática e de ampla participação social, é representativa essa constituição das entidades.

Se, por um lado, pode-se considerar um elemento positivo a presença das instituições filantrópicas e comunitárias, uma vez que promoviam uma estreita relação com a comunidade, por outro isso pode representar o favorecimento para um recrudescimento desse modelo de atendimento, estimulado pelas políticas de EI compensatória e a baixo custo. Conforme apontam Costa (2005) e Rosemberg (1999), respectivamente, isso se deu a partir da década de 1970 e contribuiu para a conformação da realidade atual.

Observa-se a inexistência de instituições classificadas como confessionais em todos os períodos históricos nos dados oficiais, embora sua existência seja visível até mesmo no nome fantasia da instituição. Uma hipótese para a entidade não assumir seu perfil religioso pode ser devido ao fato de a Lei Municipal n. ${ }^{\circ}$ 4.863/1979 — que regulamenta a certificação das entidades em Campinas como de Utilidade Pública Municipal — não permitir o fornecimento de certificação às instituições de cunho religioso, conforme seu artigo $5^{\circ}$, o que impossibilitaria a realização da formalização.

É possível observar também o protagonismo das instituições que atuam no atendimento da EI em Campinas que, de orientação católica ou espírita, até a década de 1980, cedem lugar às evangélicas e às "não identificadas", isto é, para as entidades sem perfil religioso.

Se no passado a questão da pobreza e a falta de recursos do poder público justificavam os atendimentos da criança pequena pelas instituições sem fins lucrativos, hoje as razões parecem ser outras. Observam-se as instituições sendo qualificadas e reestruturadas para assumirem a expansão da oferta e, inclusive, a oferta anteriormente pública. De um lado, verificam-se as instituições denominadas como do tipo contemporâneas na gestão das Naves-mãe/Bem Querer crescendo num ritmo acelerado; e, de outro, as de perfis do tipo históricas também sendo ampliadas para atender às novas demandas.

\section{AS INSTITUIÇÕES PRESTADORAS DE SERVIÇOS DE EDUCAÇÃO INFANTIL EM CAMPINAS: LEGISLAÇÃO E NORMAS}

\footnotetext{
4 Portal do FNDE. Disponível em: <http://www.fnde.gov.br/financiamento/fundeb/area-para-gestores/consultas>. Acesso em: 10 nov. 2018. 
Para o atendimento à demanda de vagas na EI no município de Campinas, no período de 2007 a 2018, os governos municipais estabeleceram acordos com as instituições sem fins lucrativos por meio de duas modalidades: o convênio com associações privadas históricas e tradicionais, normalizado pelo Termo de Convênio e, a partir de 2017, pelo Termo de Colaboração, e a gestão privada de equipamentos públicos, por meio do Contrato de Gestão com associações privadas e Organizações Sociais (OS).

$\mathrm{Na}$ celebração do convênio entre o governo municipal e a associação privada sem fins lucrativos (rede conveniada) até 2016, ou seja, durante quase todo o período da série histórica, na ausência de legislação específica, a SME baseava-se na Lei Municipal de Campinas n. ${ }^{\circ}$ 10.869/2001, alterada pela lei n. ${ }^{\circ} 11.279$, de 19 de junho de 2002, e na lei n. ${ }^{\circ}$ 8.666/1993, sem licitação e controle social, sob o risco de incidir em irregularidades administrativas, embora seja conhecido que a prática de conveniamento era indicada pelo MEC, conforme declaram Borghi, Bertagna e Adrião (2014).

Com o objetivo de regular esses acordos e ampliar as ações das instituições, foi aprovada a Lei Federal n. ${ }^{\circ}$ 13.019, em 31 de julho de 2014, conhecida como Marco Regulatório das Organizações da Sociedade Civil (MROSC). Essa lei estabelece normas gerais para os acordos, envolvendo ou não transferências de recursos financeiros entre a administração pública e as Organizações da Sociedade Civil (OSCs), em regime de mútua cooperação, para finalidades de interesse público. A lei instituiu o Termo de Colaboração e o Termo de Fomento e definiu as diretrizes para as políticas de parcerias, bem como alterou as leis n. ${ }^{\circ} 8.429 / 1992$ e n. ${ }^{\circ} 9.790 / 1999$ (DI PIETRO, 2015). Para os municípios, a referida lei n. ${ }^{\circ}$ 13019/2014 entrou em vigor a partir de 2017. Em atendimento a esta, no município de Campinas, os contratos com as associações privadas (conveniadas) foram renovados e atualizados a partir de 2017.

Por força do artigo 84 da lei n.o 13.019/2014, conforme Di Pietro (2015), o convênio, há muito utilizado como instrumento para vinculação entre o poder público e o privado, deixa de existir como forma de normalização e fica restrito apenas aos entes federados.

Nesse sentido, os mesmos riscos de incorrer em irregularidades ocorriam nos contratos de gestão celebrados entre PMC e associação privada ou OS para gestão das unidades públicas. Como se tratava de transferência de recursos, as normas regulatórias para o contrato de gestão não seguiam exclusivamente a Lei Federal n. ${ }^{\circ}$ 9.637/1998. No caso das OS, há um conjunto de normas que deve ser seguido e que, inclusive, não se aplica para a contratação de associação privada.

A partir de 2017, a PMC celebrou os acordos com as associações privadas e OS para gestão privada de unidades públicas de EI, com base na Lei Complementar Municipal n. ${ }^{\circ}$ 101/2015, regulamentada pelo decreto n. ${ }^{\circ} 18.740 / 2015$, alterada pelo decreto n. ${ }^{\circ} 18.786 / 2015$ e pela Lei Complementar n. ${ }^{\circ}$ 117/2015. Nesse ínterim, também se instituiu, em 2015, o Termo de Referência Técnica ${ }^{5}$, a fim de regular os contratos de gestão legalmente constituídos para a gestão dos CEI. Segundo a PMC, esse movimento se fez necessário em decorrência da nova legislação vigente (CAMPINAS, 2015a, 2015b).

Cabe apontar que a lei n..$^{\circ}$ 13.019/2014 reforça que os contratos de gestão são instrumentos utilizados para normalizar os acordos com as OS desde que cumpridos os requisitos previstos na lei n. ${ }^{\circ}$ 9637/1998, o que ficou em desacordo com contratos em vigência até 2018 na PMC.

Tanto em âmbito federal como municipal, o que se observa é que paulatinamente os mecanismos político-normativos, sobretudo a partir do PDRAE/1995, foram sendo ampliados com o intuito de instrumentalizar gestores públicos e instituições sem fins lucrativos para regular de modo mais específico as relações contratuais com o setor privado. As instituições, por sua vez, foram se adaptando e se (re)constituindo a fim de manter a prática de prestação de serviços sociais ao Estado e acessar os recursos públicos disponibilizados.

\section{A OFERTA DE VAGAS NA EDUCAÇÃO INFANTIL NO SISTEMA MUNICIPAL DE EDUCAÇÃO DE CAMPINAS DE 2007 A 2018}

\footnotetext{
5 Termo de Referência Técnica tem como objetivo disciplinar, monitorar, avaliar e controlar as ações da parceria firmada, edital 03/2015 (CAMPINAS, 2015a). 
O município de Campinas contava em 2018 com uma população aproximada de 84.374 crianças com idade de 0 a 5 anos e 11 meses, sendo 55.929 crianças de 0 a 3 anos e 28.445 de 4 a 5 anos. (SEADE, 2018) Encontravam-se matriculadas na Educação Infantil (EI) do município 56.882 crianças, sendo 27.311 na faixa etária da pré-escola e 29.571 na faixa etária da creche, no ano de 2018 (INEP, 2019).

Considerando o número de crianças em idade pré-escolar no conjunto da população aproximada e o número de matriculadas no município, verificou-se que as matrículas do segmento préescola correspondiam a 94,6\% do total de crianças do município. Notou-se, então, uma diferença de $5,4 \%$ que aparecem sem atendimento, o que causa grande estranheza, uma vez que este segmento da EI se encontrava universalizado desde 2007, conforme a SME. Uma hipótese refere-se à possível diferença no cálculo da população aproximada; e outra hipótese, que necessita ser investigada, pode estar relacionada ao fato de ter havido mudança na Resolução Municipal de Cadastro ${ }^{6}$ para oferta de vaga no município a partir de 2016, em que o cadastro da rede municipal se desmembrou do cadastro das instituições conveniadas. Com isso, na busca pela oferta do ensino integral ofertado pelas conveniadas, as famílias podem ter optado por aguardarem vaga nas entidades, e não realizarem os cadastros no Sistema Integre ${ }^{7}$, conforme a resolução determina. Importante lembrar que, conforme a Lei Municipal 11.600/2003, é dever do município garantir que todas as unidades de educação do município mantenham o cadastro permanente de crianças, como forma de verificar e planejar o atendimento da demanda. Segundo a Secretaria Municipal de Educação de Campinas (SME), desde 2007 todas as crianças de 4 a 5 anos que procuraram vaga nesse período foram atendidas.

Já o segmento creche atingiu um percentual de atendimento de 52,87\% do total de crianças na faixa etária do município em 2018. No entanto, esse percentual não representa o total da demanda por creche no município, pois, conforme dados do sistema Integre, em 2018, havia ainda uma demanda de aproximadamente 7 mil crianças aguardando vaga - o que indica que o município ainda está distante de alcançar a Meta 1 do Plano Municipal de Educação de Campinas (PME), lei 15.029/2015, que prevê “... ampliar a oferta de Educação Infantil em creches, pelo poder público municipal, de forma a atender em período integral a demanda de 0 a 03 (três) anos e 11 (onze) meses até o fim da vigência deste PME, sendo facultativo às famílias optar pelo período integral ou parcial." O percentual de 52,87\% em 2018 está acima da média do atendimento de crianças de 0 a 3 anos no Brasil, que, conforme dados do INEP ${ }^{8}$, alcançou 32,7\% nesse mesmo ano. O percentual de crianças atendidas na creche em Campinas no ano de 2018 é maior do que a meta prevista no PNE para o Brasil em 2024, que é atender 50\% das crianças na faixa etária da creche.

Para viabilizar a oferta da EI em Campinas, a SME utiliza-se de três modalidades diferentes de atendimento: rede pública direta, unidades públicas com gestão privada e rede conveniada — as duas últimas com a participação das entidades sem fins lucrativos, as quais se diferem basicamente pela propriedade e pela modalidade de vínculo estabelecido com a Prefeitura Municipal de Campinas (PMC).

A rede pública municipal direta é mantida e administrada pelo poder público e atende à etapa da EI no segmento creche de 0 a 3 anos e pré-escola de 4 a 6 anos. $O$ atendimento é realizado por docentes e especialistas do quadro do magistério público municipal e por agentes de educação infantil com ingresso por concurso público. As unidades funcionam em prédios próprios, cedidos ou alugados, geralmente bem equipados. Em 2018, a rede pública direta contava com 134 unidades e ofertava um total de 24.616 matrículas de EI, sendo 12.947 do segmento creche e 11.669 da pré-escola.

\footnotetext{
${ }^{6}$ Resolução no 21, de 15/09/2015; Resolução no 11, de 01/09/2016; Resolução no 10, de 29/08/2017.

${ }^{7}$ O Integre (Sistema de Gestão Integrada da Rede Municipal de Ensino) foi criado pela PMC em parceria com a IMA (Informática de Municípios Associados S/A) com o objetivo de informatizar a gestão das escolas municipais. Nesse sistema, são inseridos os cadastros de demanda, matrículas, relatórios individuais dos alunos, entre outros dados escolares. O Sistema oferece aos gestores relatórios estatísticos e documentos acadêmicos. Compõem também o banco de dados as Instituições Conveniadas e as Unidades Públicas com gestão Privadas (Nave-Mãe/Bem Querer).

${ }^{8}$ Disponível em: < http://portal.inep.gov.br/artigo/-/asset publisher/B4AQV9zFY7Bv/content/id/6382517>. Acesso em: 14 abr. 2019.
} 
A rede conveniada ${ }^{9}$ é composta por entidades da sociedade civil, de natureza jurídica classificada como associação privada sem fins lucrativos, que atuam vinculadas à SME. Possuem dependência própria, atendem crianças do segmento de creche e pré-escola e recebem para sua manutenção subsídios públicos per capita, alimentação escolar, uniforme e transporte escolar. Em 2018, contava-se com 45 unidades vinculadas para a oferta de 8.383 matrículas, sendo 3.688 crianças de 0 a 3 anos (creche) e 4.695 crianças de 4 e 5 anos (pré-escola), que correspondem a aproximadamente $21 \%$ do total de matrículas ofertadas pelo município. A maior parte das entidades conveniadas atende também ao segmento pré-escola em período integral. Há ainda entidades que, além do subsídio per capita, recebem recursos do Fundo Municipal da Criança e do Adolescente (FMDCA) e da Federação das Entidades Assistenciais de Campinas (FEAC) (CECCON, 2018).

Os CEI públicos com gestão privada ${ }^{10}$ - modalidade criada a partir de 2007, inicialmente denominados "Nave-mãe" pelo ex-prefeito Hélio de Oliveira Santos (PDT), e as posteriormente criadas, rebatizadas pelo prefeito Jonas Donizette (PSB) como "Bem Querer" ${ }^{11}$, caracterizam-se pelo atendimento de crianças da EI na faixa etária de 4 meses a 5 anos e 11 meses em espaços públicos, porém geridos pelas instituições de direito privado. As entidades gestoras são compostas de entidades da sociedade civil, sem fins lucrativos, de natureza jurídica como associação privada ou Organização Social (OS). Em 2018, atendiam em 28 unidades uma demanda de 9.943 crianças, sendo 6.663 do segmento creche e 3.280 do pré-escola. Recebem subsídio per capita para gestão das unidades, bem como uniformes escolares, alimentação escolar, transporte, além de acompanhamento administrativo e pedagógico e formação para a equipe escolar.

A ampliação da participação das instituições privadas sem fins lucrativos - resultado das políticas normativas em âmbito federal e municipal —, implementada pela SME de Campinas a partir de 2007, alterou o perfil da oferta de vagas na EI. O total de 56.882 matrículas ofertadas na etapa da EI dentro do Sistema Municipal de Educação de Campinas encontrava-se, em 2018, assim distribuído nas diferentes redes de atendimento: 9.943 matrículas nas unidades públicas com gestão privada; 8.383 matrículas na rede conveniada; 13.464 matrículas ofertadas na rede privada stricto sensu; e 24.616 matrículas na rede pública direta. Vale lembrar que, em 2007, o número de matrículas da rede pública direta era de 26.039 crianças. Observa-se, então, uma redução de quase 1.500 vagas no período, como pode ser constatado na Tabela 2.

Tabela 2 - Evolução das matrículas na Educação Infantil, rede estadual, rede municipal, unidades públicas com gestão privada, rede conveniada e rede particular - Campinas (2007-2018).

\begin{tabular}{|c|c|c|c|c|c|c|c|}
\hline Campinas & Período & $\begin{array}{c}\text { Total } \\
\text { Geral } \\
\text { Educação } \\
\text { Infantil }\end{array}$ & $\begin{array}{c}\text { Rede } \\
\text { Estadual }\end{array}$ & $\begin{array}{c}\text { Rede } \\
\text { Municipal } \\
\text { (exceto } \\
\text { unidades } \\
\text { públicas }\end{array}$ & $\begin{array}{l}\text { Unidades } \\
\text { públicas } \\
\text { com gestão } \\
\text { privada } \\
\text { (Nave- }\end{array}$ & $\begin{array}{c}\text { Rede } \\
\text { Conveniada }^{13}\end{array}$ & $\begin{array}{c}\text { Rede } \\
\text { Particular }^{14}\end{array}$ \\
\hline
\end{tabular}

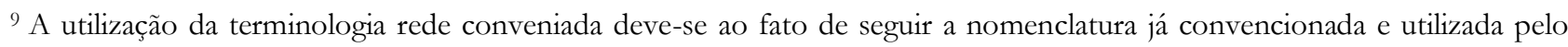
SEADE (2016).

${ }^{10}$ A opção pela nomenclatura unidades CEI público como gestão privada ocorre por dois motivos: 1) a existência de unidades públicas não "Naves-mãe", atualmente com gestão privada; e 2) para evitar confusão com o uso feito por órgãos governamentais que classificam como "indiretas" as relações entre as autarquias, fundações públicas, empresas públicas e sociedades de economia mista, no caso municipal, conforme art. 105 da Lei Orgânica do município.

11 A denominação das unidades públicas com gestão privada apresenta-se bastante confusa. No governo Jonas (PSB), os documentos oficiais ora aparecem como "Nave-mãe", ora como "Bem Querer". Acredita-se que esta confusão esteja relacionada à tentativa de não associar as novas unidades criadas ao governo do ex-prefeito Hélio (PDT).

13 Para fins de cálculo da evolução das matrículas na tabela, foram desconsiderados os anos de 2007 e 2008 na coluna da rede conveniada e rede particular por haver inconsistência nos dados, fato ocorrido no período de transição para inserção das matrículas conveniadas no censo escolar, separadas das matrículas privadas.

${ }^{14}$ De acordo com o censo escolar, a categoria privada inclui as escolas particulares stricto sensu, as comunitárias, confessionais e filantrópicas. Este trabalho considera como matrículas privatizadas as ofertadas pela rede conveniada e pelas unidades públicas com gestão privada (Nave-mãe/Bem Querer).

Educação em Revista|Belo Horizonte|v.36|e231107|2020
} 


\begin{tabular}{|l|l|l|l|l|c|c|c|}
\hline & & & & $\begin{array}{c}\text { com } \\
\text { gestão } \\
\text { privada) }\end{array}$ & $\begin{array}{c}\text { mãe/ Bem } \\
\text { Querer) }\end{array}$ & & \\
\hline & 2007 & 38.256 & - & 26.039 & - & 11.943 & 274 \\
\hline & 2008 & 40.923 & - & 25.493 & 1.605 & 2.377 & 11.448 \\
\hline & 2009 & 39.857 & & 23.119 & 3.009 & 6.158 & 7.587 \\
\hline & 2010 & 42.667 & 4 & 25.849 & 4.123 & 4.965 & 7.726 \\
\hline & 2011 & 44.538 & - & 25.362 & 5.474 & 5.629 & 8.073 \\
\hline & 2012 & 46.796 & - & 24.717 & 6.000 & 6.236 & 9.843 \\
\hline & 2013 & 47.419 & - & 23.911 & 6.811 & 6.460 & 10.237 \\
\hline & 2014 & 48.450 & - & 23.482 & 7.159 & 6.806 & 11.003 \\
\hline $\begin{array}{l}\text { Percentual } \\
\text { de }\end{array}$ & 2015 & 49.926 & - & 23.614 & 7.561 & 7.002 & 11.749 \\
\hline & 2016 & 52.651 & - & 24.028 & 8.864 & 7.674 & 12.085 \\
\hline
\end{tabular}

Fonte: SEADE (2017) ${ }^{15}$ e Censo Escolar $(2018)^{16}$.

No período analisado, o total de matrículas na EI apresentou um crescimento de 48,68\%, o que representa cerca de 18 mil novas vagas. Contudo, observou-se que a ampliação se deu exclusivamente pelo setor privado, sendo 519,5\% pelas unidades públicas com gestão privada (Nave-mãe/Bem Querer), pela rede particular - que aumentou em 77,46\% o número de vagas ofertadas em 2018 quando comparada com 2009 - e pela rede conveniada, que cresceu 36,13\%, também em comparação a 2009. A rede pública direta não criou nenhuma vaga nova, se comparada com 2007; pelo contrário, teve redução de 5,46\%, conforme se pode visualizar no Gráfico 1.

Gráfico 1 - Evolução das matrículas na Educação Infantil: pública direta, privatizada ${ }^{17}$ e particular Campinas (2007-2018).

\footnotetext{
12 Os dados de matrícula das unidades públicas com gestão privada foram compostos a partir da exclusão das matrículas públicas diretas, uma vez que são computadas como matrículas públicas no censo escolar.

15 Os dados de 2007 a 2016 foram coletados na plataforma do SEADE.

${ }^{16}$ Os dados de 2017 e 2018 foram coletados a partir dos microdados do censo escolar por dois motivos: a) a informação das matrículas da rede conveniada deixou de existir na base de dados do SEADE de forma separada a partir de 2017; b) até o momento da coleta - março/2019 - , a plataforma ainda não continha os dados de 2018.

${ }^{17}$ Considera-se matrícula privatizada aquela ofertada pela rede conveniada e pelas unidades públicas com gestão privada. 


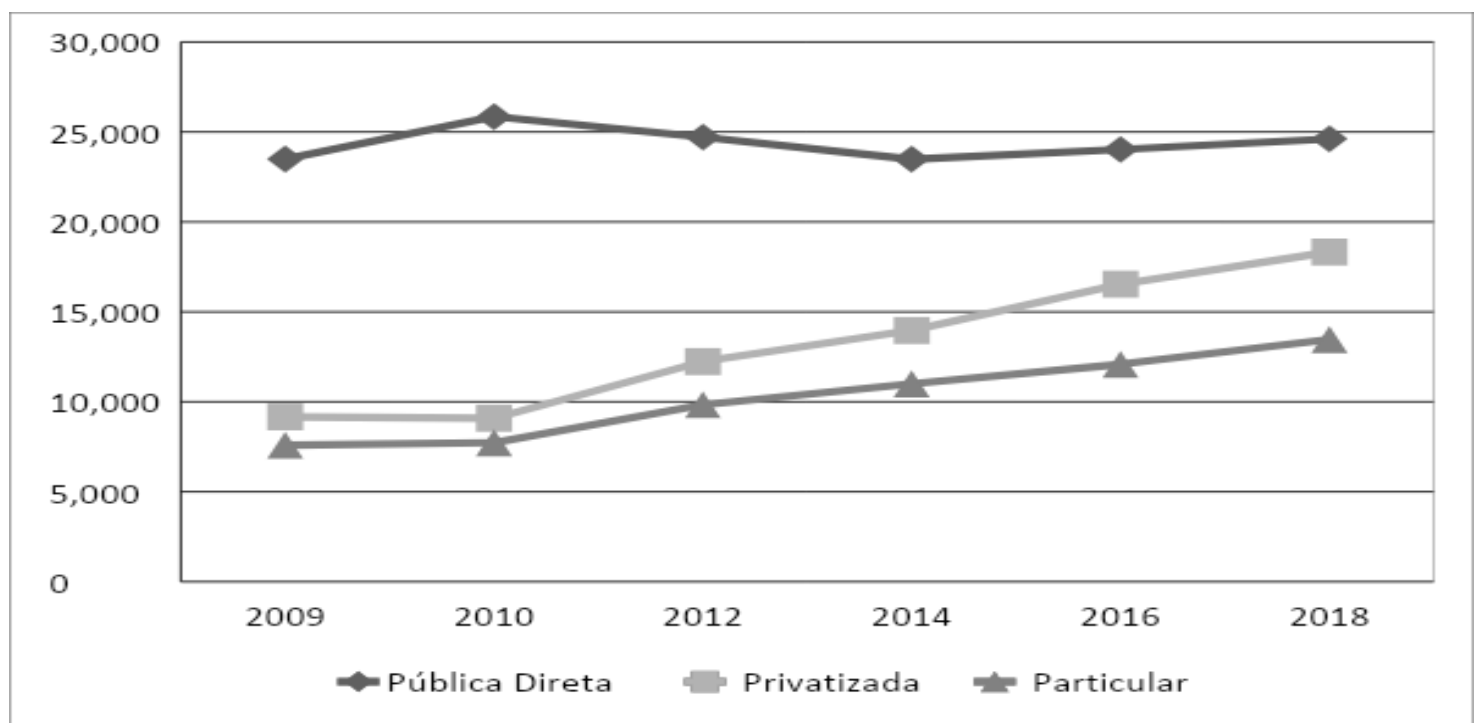

Fonte: SEADE (2017), Censo Escolar (2018).

O gráfico mostra o crescimento da oferta de vagas privatizadas e também das vagas oferecidas pela rede particular, configurando uma ampliação do éthos privado na oferta da educação infantil em Campinas. Entende-se que esse movimento de expansão do setor privado, principalmente por meio das instituições sem fins lucrativos, representa claramente a opção do governo municipal, assumida a partir de 2007, que privilegiou basicamente esse tipo de oferta de vagas. O fortalecimento desse formato de oferta alterou o perfil da EI do município, que até então primava pela oferta pública.

Como justificativa para essa guinada ao setor privado, o município usou em 2007 a Lei de Responsabilidade Fiscal, lei n. ${ }^{\circ} 101 / 2000$, que determina um teto para gasto com pessoal de até $60 \%$ do orçamento de estados e municípios, incluindo-se $6 \%$ relativos aos funcionários do legislativo. No caso de Campinas, Domiciano-Pellisson (2016) e Chicone (2016) sinalizaram que essa alegação não se justificava, uma vez que o município não atingia o percentual de gastos permitidos pela referida lei. Ademais, com a redução de aproximadamente 1.500 vagas na oferta direta pública de EI registrada em 2018, reduziu-se também o gasto com pessoal. Domiciano-Pellisson (2016) aponta que, em 2007, o gasto com pessoal representava 75\% do orçamento da educação no município de Campinas; já em 2014, esse percentual caiu para 46\%. Portanto, o atendimento às exigências da LRF não é mais uma justificativa plausível para a redução de gastos com pessoal em educação pública direta, o que corrobora com o posicionamento de Adrião (2009), ao afirmar que a restrição imposta pela LRF para gastos com pessoal induziu o aumento da canalização de fundos públicos para o setor privado por meio da terceirização de contratos e de serviços especialmente nas áreas de maior presença de contratação, como é o caso da educação (ADRIÃO, 2009). Isso parece ter sido o que ocorreu com a oferta de EI no município de Campinas. A economia de recursos produzida com a redução de gastos com pessoal da educação da rede pública direta parece ter sido aplicada na oferta privada, por meio da rede conveniada e das unidades com gestão privada (Nave-mãe/Bem Querer).

Outro fator que também pode ser considerado como motivação para o aumento da oferta de matrículas privatizadas, a partir de 2007, refere-se ao modelo de financiamento da EI, instituído pelo Fundo de Manutenção e Desenvolvimento da Educação Básica e de Valorização dos Profissionais da Educação (FUNDEB), regulamentado pela lei n. ${ }^{\circ} 11.494$ de 2007, já indicado por Arelaro (2008). O artigo $8^{\circ}$ da referida lei possibilitou o cômputo das matrículas das instituições sem fins lucrativos que ofertam EI, desde que conveniadas com o poder público. Esse fator, estimulado por alterações na legislação em âmbito federal e municipal, manobras e arranjos com o setor privado sem fins lucrativos na gestão de unidades públicas, acabou por ser decisivo para a ampliação da privatização da oferta da EI no município Campinas.

No caso de Campinas, esse movimento de privatização tem-se manifestado de forma sistemática, com tendência a substituir a oferta pública direta orientada pelo direito público, pela oferta privada, por meio das instituições sem fins lucrativos regidas pelo direito privado. Embora se saiba que 
a oferta da EI por meio de subsídios/subvenções municipais ao setor privado sem fins lucrativos não seja algo novo, verifica-se um significativo crescimento dessa modalidade, com inovações no campo da legislação e diferentes arranjos no setor, indicando uma tendência à consolidação desse modelo como opção de atendimento a essa etapa da educação básica.

É imperativo discutir essa questão uma vez que a transferência da oferta pública direta do atendimento da Educação Infantil de Campinas para as instituições privadas sem fins lucrativos retira desse segmento direitos conquistados historicamente. Aspectos fundamentais para assegurar a qualidade do atendimento, como espaços físicos adequados, mobiliário, jornada, remuneração e formação docente, número de alunos por sala, entre outros insumos indicados no Custo Aluno Qualidade Inicial (CAQi) e Custo Aluno Qualidade (CAQ), previstos no Plano Nacional de Educação (PNE) 2014/2024, deixam de ser considerados nesse modelo. Embora não faça parte do escopo deste trabalho a análise sobre o custo da vaga da oferta direta e da oferta privatizada, observam-se indícios de que houve transferência significativa de recursos públicos ao setor privado.

As entidades conveniadas ou até mesmo cada instituição gestora oferecem condições diferenciadas no que se refere aos insumos básicos necessários para o atendimento dessa etapa, sem a obrigação de atender a um determinado padrão de qualidade imposto às unidades da rede pública direta. Nesse sentido, é possível afirmar que a opção política assumida pelo governo municipal desde 2007 impõe parte significativa das crianças do município à precarização no atendimento e à profunda desigualdade educacional.

\section{CONSIDERAÇÕES FINAIS}

Acompanhando as transformações políticas, normativas e sociais, as instituições sem fins lucrativos do município de Campinas passam a ocupar espaço importante no atendimento da EI, mais especificamente no período de 2007 a 2018. Diferentemente do que se imaginava — que as instituições sem fins lucrativos ocupavam espaços a que o Estado não chegava —, verifica-se um processo de crescimento enorme no período, alcançando $452 \%$ para as instituições com contrato de gestão das unidades públicas e $24 \%$ para as conveniadas.

Em 2007, o setor privado sem fins lucrativos e stricto sensu respondia por 31,93\% das matrículas, enquanto o setor público direto ofertava 68,07\%. Em 2018, o primeiro passou a ofertar $56,64 \%$ do total matrículas, superando a oferta pública direta, que passa a representar apenas 43,64\%, uma redução de aproximadamente 1.500 vagas no período. Fica evidente que a inclusão da rede conveniada sem fins lucrativos no Fundeb contribuiu significativamente para a expansão desta rede no atendimento à Educação Infantil em Campinas a partir de 2007. Isso confirma o que Pinto (2007) previa no início da vigência do Fundeb: que, com a enorme demanda reprimida, especialmente nas creches em função do baixo atendimento, "o crescimento das matrículas se dê pela via das instituições conveniadas, já que o repasse que o poder público faz a essas instituições é muito inferior aos custos do atendimento direto" (PINTO, 2007, p. 888). De fato, foi o que ocorreu no município de Campinas, representando um duro golpe no princípio constitucional de que os recursos públicos devam se destinar às instituições públicas (PINTO, 2007).

O município de Campinas não só ampliou o atendimento pela via da rede conveniada, como "inaugurou a modalidade de gestão privada em unidades públicas", segundo Domiciano-Pellisson (2016), e ainda, reduziu a oferta pública direta na série histórica. A hipótese levantada por Pinto (2007), de que o baixo custo seria a motivação principal para a transferência de recursos para instituições conveniadas, não se confirmou no município de Campinas. Estudos de Domiciano-Pellisson (2016) e Ceccon (2018) evidenciaram que os valores repassados às instituições sem fins lucrativos são bem maiores que os valores repassados pelo Fundeb, e maiores que os previstos pelo CAQi. Nesse sentido, concorda-se com Di Pietro (2015) que a transferência da gestão de serviços públicos às organizações sociais civis deixa evidente a intenção dos governantes de escaparem do regime jurídico imposto às entidades da administração direta e indireta, como licitação, concurso público e controle, e permitirem que o serviço público seja ofertado sob o regime jurídico de direito privado. Além do mais, esse modelo distancia o governo da cobrança direta da população, uma vez que ele passa a ser apenas fornecedor de recursos. 
Qualquer problema que venha a acontecer no fornecimento das atividades não o coloca como responsável direto, e assim se diminuem os riscos de o governo ter sua reputação manchada.

Outro aspecto observado no conjunto das transformações ocorridas no perfil das instituições que ofertam a EI no período é a presença de empresas (classificadas como contemporâneas) cujos objetivos necessitam de rigorosa análise, o que não coube nos limites deste artigo. No movimento de ampliação do setor privado, aqui analisado para a oferta da Educação Infantil em Campinas, verificouse a consolidação da política de "privatização" da oferta de vagas nessa etapa da educação básica.

Evidencia-se, por fim, que a opção dos governos municipais na série histórica foi de ampliação da política de atendimento pela via do setor privado sem fins lucrativos, que em 2018 chegou a manter mais de 18 mil crianças à margem do sistema público oficial de ensino, em um movimento que reforça e contribui para a manutenção da desigualdade educacional e social no município.

\section{REFERÊNCIAS}

ADRIÃO, T. Indicações e reflexões sobre as relações entre esferas públicas e privadas para a oferta educacional no Brasil. Políticas Educativas, Porto Alegre: UFRGS, v. 3, n.1, p. 48-64, 2009.

ADRIÃO, T. Dimensões da educação básica no Brasil a partir de 1990: um diálogo com a produção acadêmica. 2015. Tese (Livre-Docência) — Faculdade de Educação, Universidade Estadual de Campinas, 2015.

ADRIÃO, T.; BEZERRA, E. P. O setor não lucrativo na gestão da educação pública: corresponsabilidade ou debilidade. Currículo sem Fronteiras, v. 13, n. 2, p. 256-268, maio/ago. 2013.

ARELARO, L. A não-transparência nas relações público-privadas: o caso das creches conveniadas. In: ADRIÃO, T.; PERONI, V. (org.). Público e Privado na Educação: novos elementos para o debate. São Paulo: Xamã, 2008, v. 1, p. 51-66.

BORGHI, R.; BERTAGNA, R.; ADRIÃO, T. Subsídios públicos às instituições privadas de educação infantil: um estudo em municípios paulistas. In: SILVA, S. M.; SILVA, M. V. (Orgs.), Trabalho docente e políticas educacionais para educação infantil: desafios contemporâneos. Uberlândia: EDUFU, 2014. p. 131-150.

BRASIL. Presidência da República. Constituição da República Federativa do Brasil de 1988. Diário Oficial da União, Brasília, DF, 5 out. 1988.

BRASIL. Lei n. ${ }^{\circ}$ 8.666, de 21 de junho de 1993. Regulamenta o art. 37, inciso XXI, da Constituição Federal, institui normas para licitações e contratos da Administração Pública e dá outras providências. Diário Oficial da União, Brasília, DF, 22 jun. 1993. Disponível em:

http://www.planalto.gov.br/ccivil_03/leis/L8666cons.htm. Acesso em: 19 nov. 2018.

BRASIL. Presidência da República. Câmara da Reforma do Estado. Plano Diretor da Reforma do Aparelho do Estado - PDRAE. Brasília, DF: MEC, 1995.

BRASIL. Lei n..$^{\circ}$ 9.394, de 20 de dezembro de 1996. Estabelece as Diretrizes e Bases da Educação Nacional. Diário Oficial da União, Brasília, DF, 23 dez. 1996.

BRASIL. Lei n. ${ }^{\circ}$ 9.637, de 15 de maio de 1998. Dispõe sobre a qualificação de entidades como organizações sociais, a criação do Programa Nacional de Publicização, a extinção dos órgãos e entidades que menciona e a absorção de suas atividades por organizações sociais, e dá outras providências. Diário Oficial da União, Brasília, DF, 25 maio de 1998. 
BRASIL. Lei n. ${ }^{\circ}$ 10.406, de 10 de janeiro de 2002. Institui o Código Civil. Diário Oficial da União: seção 1, Brasília, DF, ano 139, n. 8, p. 1-74, 11 jan. 2002. PL 634/1975.

BRASIL. Emenda constitucional n. ${ }^{\circ}$ 53, de 19 de dezembro de 2006. Dá nova redação aos artigos. $7^{\circ}$, 23, 30, 206, 208, 211 e 212 da Constituição Federal e ao art. 60 do Ato das Disposições Constitucionais Transitórias. Diário Oficial da União, Brasília, DF, 20 dez. 2006.

BRASIL. Lei n. ${ }^{\circ}$ 11.494, de 20 de junho de 2007. Regulamenta o Fundo de Manutenção e Desenvolvimento da Educação Básica e de Valorização dos Profissionais da Educação - FUNDEB, e dá outras providências. Diário Oficial da União, Brasília, DF, 21 jun. 2007. Disponível em: http://www.planalto.gov.br/ccivil_03/_ato2007. Acesso em: 12 nov. 2018.

BRASIL. Lei n. ${ }^{\circ} 12.101$, de 27 de novembro de 2009, para dispor sobre o processo de certificação das entidades beneficentes de assistência social e sobre procedimentos de isenção das contribuições para a seguridade social. Diário Oficial da União, Brasília, DF, 26 maio 2014. Disponível em: http://www.planalto.gov.br/ccivil_03/_ato2011-2014/2014/decreto/d8242.htm. Acesso em: 11 nov. 2018.

BRASIL. Lei n. ${ }^{\circ}$ 13.005, 25 de junho de 2014. Aprova o Plano Nacional de Educação - PNE, e dá outras providências. Diário Oficial da União, Brasília, DF, 26 jun. 2014.

BRASIL. Lei n. ${ }^{\circ}$ 13.019, de 31 de julho de 2014. Estabelece o regime jurídico das parcerias voluntárias, envolvendo ou não transferências de recursos financeiros, entre a administração pública e as organizações da sociedade civil, em regime de mútua cooperação, para a consecução de finalidades de interesse público; define diretrizes para a política de fomento e de colaboração com organizações da sociedade civil; institui o termo de colaboração e o termo de fomento; e altera as leis n. 8.429, de 2 de junho de 1992, e n. 9.790, de 23 de março de 1999. Diário Oficial da União, Brasília, DF, $1^{\circ}$ ago. 2014. Disponível em: http://www.planalto.gov.br/ccivil_03/_ato2011-2014/2014/lei/113019.htm. Acesso em: 18 nov. 2018.

BRASIL. O que é o CEBAS Educação? Cartilha Prática sobre a Certificação de Entidades Beneficentes de Assistência Social na Área da Educação. Brasília, DF: 2015. Disponível em: http://cebas.mec.gov.br/images/pdf/cartilha_cebas_versao_11022015.pdf. Acesso em: 19 nov. 2018.

CAMPINAS. Decreto-Lei n. ${ }^{\circ}$ 239, de 31 março 1944. Regula a cooperação financeira do município com entidades destinadas à assistência social ou cultural. Disponível em: https://bibliotecajuridica.campinas.sp.gov.br/index/visualizaratualizada/id/95979. Acesso em: 1 nov. 2018.

CAMPINAS. Lei n. $^{\circ}$ 4.863, de 8 de fevereiro de 1979. Dispõe sobre a declaração de utilidade pública de sociedade civil, associação, fundação e dá outras providências. Secretaria da Câmara Municipal de Campinas, Campinas, 8 fev. 1979. Disponível em: https://bibliotecajuridica.campinas.sp.gov.br/index/visualizaratualizada/id/88131. Acesso em: 19 nov. 2018.

CAMPINAS. Lei n. ${ }^{\circ} \mathbf{1 0 . 8 6 9}$, de 19 de junho de 2001. Dispõe sobre o repasse de recursos orçamentários da secretaria municipal de educação às entidades, instituições e grupos comunitários legalmente constituídos. Diário Oficial do Município de Campinas, Campinas: 30 jun. 2001. Disponível em: https://bibliotecajuridica.campinas.sp.gov.br/index/visualizaratualizada/id/91689. Acesso em: 19 nov. 2018. 
CAMPINAS. Lei n. ${ }^{\circ}$ 11.279, de 19 de junho de 2002. Acrescenta os incisos vi e vii ao artigo $2^{\circ}$ e dá nova redação ao artigo $3^{\circ}$ da lei municipal n. ${ }^{\circ} 10.869$, de 29 de junho de 2001, que dispõe sobre o repasse de recursos orçamentários da secretaria municipal de educação às entidades, instituições e grupos comunitários legalmente constituídos. Diário Oficial do Município de Campinas, Campinas: 20 jun. 2002. Disponível em:

https://bibliotecajuridica.campinas.sp.gov.br/index/visualizaratualizada/id/89718. Acesso em: 19 nov. 2018.

CAMPINAS. Lei complementar n. $^{\circ}$ 101, de 19 de março de 2015. Dispõe sobre a qualificação de entidades como organizações sociais e dá outras providências. Diário Oficial do Município de Campinas, Campinas. 20 mar. 2015b. Disponível em:

https://bibliotecajuridica.campinas.sp.gov.br/index/visualizaratualizada/id/128249. Acesso em: 19 nov. 2018.

CAMPINAS. Decreto n. $^{\mathbf{0}} \mathbf{1 8 . 7 4 0}$, de 18 de maio de 2015. Regulamenta a lei complementar n. $^{\circ} 101$, de 19 de março de 2015, que dispõe sobre a qualificação de entidades como organizações sociais e dá outras providências. Diário Oficial do Município de Campinas, Campinas, 20 maio 2015. Disponível em: https://bibliotecajuridica.campinas.sp.gov.br/index/visualizaratualizada/id/128494. Acesso em: 19 nov. 2018.

CAMPINAS. Decreto n. ${ }^{\mathbf{1}} \mathbf{1 8 . 7 8 6}$, de 8 de julho de 2015. CAMPINAS. Altera o decreto n. ${ }^{\circ}$ 18.740, de 19 de maio de 2015, que regulamenta a lei complementar n. 101, de 19 de março de 2015, que "dispõe sobre a qualificação de entidades como organizações sociais e dá outras providências". Diário Oficial do Município de Campinas, Campinas, 13 jul. 2015. Disponível em: https://bibliotecajuridica.campinas.sp.gov.br/index/visualizaratualizada/id/128670. Acesso em: 19 nov. 2018.

CAMPINAS. Lei complementar $\mathbf{n}^{\circ}{ }^{117}$, de 18 de setembro de 2015 . Altera a lei complementar $n$. $^{\circ}$ 101, de 19 de março de 2015, que "Dispõe sobre a qualificação de entidades como organizações sociais, e dá outras providências". Diário Oficial do Município de Campinas, Campinas, 21 set. 2015c. Disponível em: https://bibliotecajuridica.campinas.sp.gov.br/index/visualizaroriginal/id/128912. Acesso em: 19 nov. 2018.

CAMPINAS. Termo de Referência Técnica 2016. Campinas: edital 03/2015. Disponível em: http://campinas.sp.gov.br/arquivos/educacao/termo_referencia_proinfe.pdf. Acesso em: 19 nov. 2018.

CAMPINAS. Termo de Referência Técnica 2016. Campinas: edital 04/2015. Disponível em: http://campinas.sp.gov.br/arquivos/educacao/edital_04_2015.pdf. Acesso em: 19 nov. 2018.

CECCON, M. L. L. Instituições sem fins lucrativos na oferta da educação infantil, no município de Campinas: histórico, dilemas e perspectivas. 2018. 245f. Dissertação (Mestrado em Educação) Faculdade de Educação, Universidade Estadual de Campinas, Campinas, 2018.

CHICONE, S. H. A participação das organizações não governamentais na gestão da escola pública: uma análise do Programa "Nave-Mãe" no município de Campinas - SP. 2016. $246 f$. Dissertação (Mestrado em Educação) - Universidade de São Paulo, São Paulo, 2016.

COSTA, M. Criar o público não estatal ou tornar público o estatal? In: ADRIÃO, T.; PERONI, V. O público e o privado na educação. São Paulo: Xamã, 2005, p. 13-30. 
DI PIETRO, M. S. Z. Parcerias na administração pública: concessão, permissão, franquia, terceirização, parceria-público privada e outras formas. São Paulo: Atlas, 2015.

DOMICIANO-PELLISSON, C. A. A cogestão dos Centros de Educação Infantil "Nave-mãe": uma parceria público-privada analisada. 2016. 226f. Tese (Doutorado em Educação) - Faculdade de Educação, Universidade Estadual de Campinas, Campinas, 2016.

FNDE. Fundo Nacional de desenvolvimento da Educação. Fundeb. c2017. Consultas. Disponível em: <http://www.fnde.gov.br/financiamento/fundeb/area-para-gestores/consultas>. Acesso em: 10 nov. 2018.

IBGE. Monografia histórica do município de Campinas. Rio de Janeiro: Serviço Gráfico do Instituto Brasileiro de Geografia e Estatística, 1952.

PINTO, J. M. R. A política recente de fundos para o financiamento da educação e seus efeitos no pacto federativo. Educação \& Sociedade. Campinas, v.28, n.100-Especial, p.877-897, out. 2007.

ROSEMBERG, F. Expansão da educação infantil e processos de exclusão. Cadernos de Pesquisa, São Paulo: Fundação Carlos Chagas; Campinas: Autores Associados, n. 107jul./1999 , p. 7-40.

SILVA, C. O. P. A reforma administrativa e a Emenda 19/98: uma análise panorâmica. Revista Jurídica Virtual, Brasília, v. 1, n. 1, maio 1999, p. 1-20. 